\title{
The European Respiratory Society fellowship programme: supporting young careers and building networks
}

\author{
Robert Bals', Josephine Ricou Yanmaz², Céline Schaffter², Carine Pannetier², \\ Nadia Kamel ${ }^{3}$, Roelinde Middelveld ${ }^{4}$, Sven-Erik Dahlén ${ }^{4}$, Bart N. Lambrecht ${ }^{5}$, \\ Benoit Nemery ${ }^{6}$, Laurent Nicod ${ }^{7}$ and Stephen Holgate ${ }^{8}$
}

\begin{abstract}
Affiliations: 'Dept of Internal Medicine V - Pulmonology, Allergology, Respiratory Intensive Care Medicine, Saarland University Hospital, Homburg, Germany. ${ }^{2}$ Scientific Activities Dept, European Respiratory Society, Lausanne, and ${ }^{7}$ Division of Pneumology, Centre Hospitalier Universitaire Vaudois, University of Lausanne, Lausanne, Switzerland. ${ }^{3}$ EU Affairs Dept, European Respiratory Society, Brussels, ${ }^{5} \mathrm{VIB}$ Dept for Molecular, Biomedical Research, UGent, UGent-VIB Research Building FSVM, Gent, and ${ }^{6}$ Research Unit of Lung Toxicology, Dept of Public Health, Leuven, Belgium. ${ }^{4}$ The Center for Allergy Research and The Institute of Environmental Medicine, Karolinska Institutet, Stockholm, Sweden. ${ }^{8}$ Southampton General Hospital, Southampton, UK
\end{abstract}

Correspondence: R. Bals, Dept of Internal Medicine V - Pulmonology, Allergology, Respiratory Intensive Care Medicine, D-66421 Homburg, Germany. E-mail: robert.balsQuks.eu

0 @ERSpublications

The ERS fellowship scheme is one of the world's largest and most successful support programmes http://ow.ly/myOy0

\section{Introduction}

The European Respiratory Society (ERS) fellowship programme aims to promote research and training in respiratory diseases by fostering scientific international mobility, boosting the careers of the young recipient fellows, creating scientific networks, and retaining promising researchers in Europe. Since 1997 the ERS has supported more than 450 qualified investigators, clinicians, and allied health professionals with the focus on scientific mobility and early-stage career development. With a budget of $€ 950000$ in 2013, the ERS fellowship programme is one of the major initiatives and investments that the ERS makes to support the next generation of scientists and physicians in the respiratory field within Europe.

\section{Structure of the ERS fellowship programme}

The ERS fellowship programme comprises short- and long-term research fellowships (STRTF and LTRF, respectively) enabling the recipient to carry out research projects in basic, clinical and translational science (fig. 1). In a collaboration with the European Union (Marie Curie Actions Co-funding of Regional, National, and International programmes (COFUND)), postdoctoral fellowships offer 2-year funding opportunities to highly talented postdoctoral fellows. The LTRF include grants for 6-month to 1-year research projects to competitive young postgraduate, doctoral, and postdoctoral fellows, supporting their career development in top-level host institutes. The STRTF offer grants for 1-month to 3-month durations, which target highly motivated and qualified young postgraduate and doctoral fellows, enabling them to be trained in advanced, research techniques. The aim is for these young professionals to transfer their newly acquired knowledge and knowhow back to their home institute.

Precious collaborations with three national societies SEPAR (Spanish Society of Pneumology and Thoracic Surgery), AIMAR (Italian Multidisciplinary Association for the Study of Respiratory Diseases), and CTS

Received: June 192013 | Accepted: June 202013

Conflict of interest: J. Ricou Yanmaz, C. Schaffter, C. Pannetier and N. Kamel are employees of the European Respiratory Society. Further disclosures can be found alongside the online version of this article at www.erj.ersjournals.com 


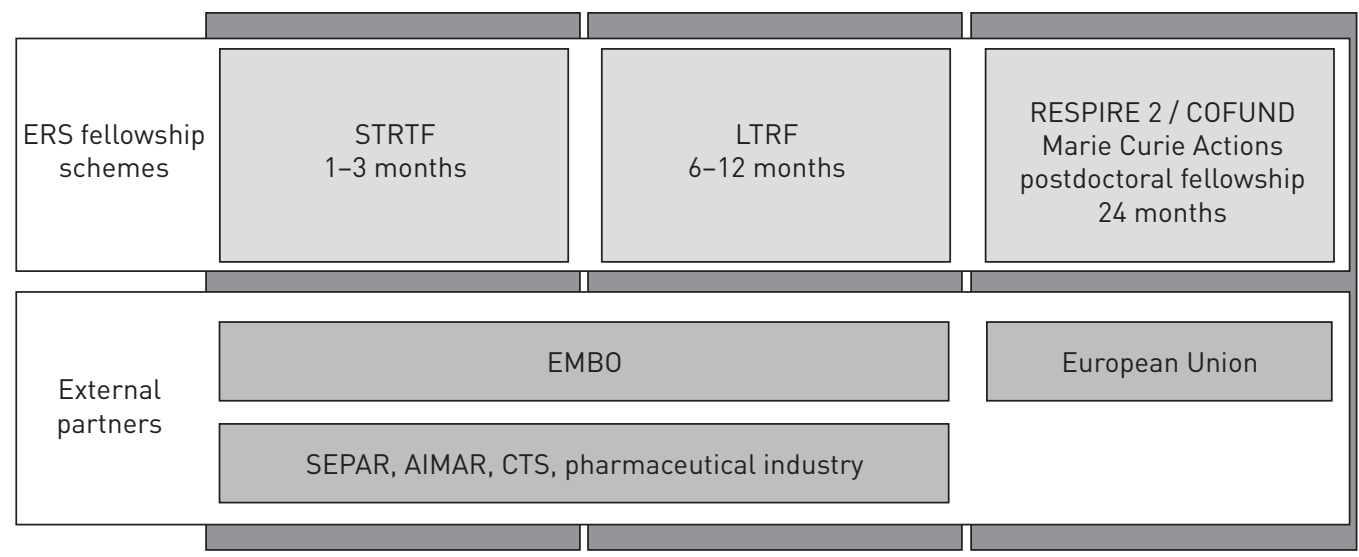

FIGURE 1 Structure of the European Respiratory Society (ERS) fellowship programme. The programme comprises shortterm research training fellowships (STRTF) and long-term research fellowships (LTRF), and a 2-year RESPIRE 2 Marie Curie Actions Co-funding of Regional, National, and International programmes (COFUND) postdoctoral fellowship. Several fellowships are offered in collaboration with the listed partners. EMBO: European Molecular Biology Organization; SEPAR: Spanish Society of Pneumology and Thoracic Surgery; AIMAR: Italian Multidisciplinary Association for the Study of Respiratory Diseases; CTS: Canadian Thoracic Society.

(Canadian Thoracic Society), with the European society EMBO (European Molecular Biology Organization), with industry (GlaxoSmithKline) and with the European Commission (European Union 7th Framework Programme (FP7) PEOPLE COFUND Marie Curie Actions) have allowed the ERS fellowship programme to build additional capacity and expertise.

The COFUND fellowship series, termed RESPIRE 1 and 2, were the outcome of a competitive application within the FP7 and allowed to expand the ERS programme in quantitative and qualitative aspects. For the first time since the launch of the ERS fellowship programme, the RESPIRE 2 scheme is able to offer a 2-year postdoctoral fellowship that ensure a comprehensive training at research departments that are committed to provide excellent working conditions. A full salary is provided to the fellows and additional career-building elements, such as training in soft skills, deep evaluation of the programme and the project, complement this novel fellowship.

For all fellowship types, researchers based in Europe or elsewhere are eligible for a fellowship if they wish to move to a European country, other than their own, in order to build new collaborations, evolve within a new scientific environment and produce original research advancing their careers and science in the respiratory field. A few fellowship opportunities are also available for European-based scientists to move overseas with a mandatory return component. Applicants have to submit a proposal to join a specific host laboratory and the potential host must express support for a named applicant to do research in the laboratory (no bench fees are provided by the ERS). The ERS does not fund research projects as such.

Applications are evaluated in a robust and transparent process that depends largely on the work of the ERS Evaluation Committee composed by distinguished experts in their respective fields. There is no discrimination according to age, sex, ethnic origin, religious, or political beliefs of the applicants. All applications undergo an impartial and rigorous peer-review process by recognised international experts, free of any conflicts of interest. Candidates are evaluated and selected by the Evaluation Committee based on scientific merit and transparent criteria solely. For details regarding application deadlines, administrative requirements, amount of the allowances, the reader is referred to the ERS website: www.ersnet.org/ fellowships.

\section{Outcome measurements}

As the ERS invests significant resources in the fellowship programme, its outcomes are evaluated taking into account that measuring scientific and career success is difficult [1]. Since 2007, a specific session has been organised during the annual congress of the ERS to allow past and current fellows to present their work and, importantly, their experiences to each other and to potential applicants. At the end of 2012, a survey was sent to 273 former fellows from the years 2006 to 2012 and $46 \%$ completed questionnaires were returned. The most frequent nationalities of the fellows and the most favoured country of the host institute are displayed in table 1 . The mean \pm SD age at the commencement of the fellowship was $33.2 \pm 5.5$ with $52 \%$ fellows being female. A comparison of the career stage before and after the fellowship showed that most fellows could further develop their careers and obtain better positions after their fellowship placement. $42 \%$ 
TABLE 1 Top 10 nationalities for fellows and countries of the host institutes

Rank

Nationality of fellow

\begin{tabular}{lcc} 
& Country & $\%$ \\
\hline $\mathbf{1}$ & Greece & 11.8 \\
$\mathbf{2}$ & India & 10.2 \\
$\mathbf{3}$ & The Netherlands & 7.9 \\
$\mathbf{4}$ & Italy & 7.9 \\
$\mathbf{5}$ & Brazil & 4.7 \\
$\mathbf{6}$ & Hungary & 3.6 \\
$\mathbf{7}$ & Germany & 3.1 \\
$\mathbf{8}$ & Ireland & 2.4 \\
$\mathbf{9}$ & Argentina & 2.4 \\
$\mathbf{1 0}$ & China & 1.6
\end{tabular}

Geographical distribution of the host institutes

\begin{tabular}{cc}
\hline Country & $\%$ \\
UK & 30.8 \\
France & 11.2 \\
Germany & 10.3 \\
Belgium & 9.3 \\
Italy & 8.4 \\
Spain & 7.5 \\
The Netherlands & 4.7 \\
Switzerland & 3.7 \\
Austria & 2.8 \\
USA & 2.8 \\
\hline
\end{tabular}

of the fellows indicated that the ERS fellowship programme had helped their career development "much" or "very much". In addition to personal training, the programme generated a significant bibliographic output, mostly originating from the LTRFs. The free comments on the fellowship programme and the completed questionnaires were consistently very positive. Thus, many fellows point to "intangible" benefits that have accrued for themselves and their families, such as learning another language and making friends.

\section{Strategic and future development}

As medicine, science, and the social environment are steadily changing, the ERS fellowship scheme is continuously adapting its strategy to meet the needs of the ERS members and future fellows. The principal aims of the ERS fellowship programme are to improve all aspects of science in the field of respiratory medicine, to build and support young scientists, and to establish research networks. Based on these general principles, the specific strategic aims of the ERS fellowship programme are as follows.

1) To increase scientific networking in Europe. As one goal of the ERS fellowship programme is the building of networks between researchers, clinicians, patients, organisations, and other stakeholders, the ERS is becoming more and more active in the area of social media (https://twitter.com/ERSTalk; https://www. facebook.com/EuropeanRespiratorySociety). The novel RESPIRE 2 programme within the FP7, as well as all other fellowship types, supports free exchange within European countries.

2) To focus on individuals. While the fellowship programme has always focused on supporting individual researched, the ERS aims to provide a comprehensive package focusing on career development. This is one major goal of RESPIRE 2, which is characterised by a 2-year postdoctoral fellowship with full salary and by additional career development tools. The ERS also recognises the importance of creating opportunities for those from countries with less grounding in research methods wishing to acquire new research skills, and is examining possible ways of supporting such individuals.

3) To foster research in the respiratory field. Because respiratory research is significantly underfunded when compared to the burden of disease worldwide and research in other disciplines (www.ersroadmap.org), one important aim of the programme is to stimulate scientists from all fields (biomedical, applied and physical sciences) to rise to the challenge of tackling the large unmet needs of lung disease and to increase outcomes and visibility. The collaboration with EMBO is a good example of how the ERS aims to involve partners outside the classic respiratory field.

4) To support respiratory clinicians and allied health professionals in their aspirations to develop a career in science. Physician-scientists have been one driving force in biomedical research. Several factors are responsible for respiratory physicians being generally less active in research, such as pressures to deliver a clinical service, yet for better health there has to be investment in research and education [2]. Therefore, one key aim of the ERS fellowship programme is to provide physicians that have received some basic training in research, normally in the form of a completed $\mathrm{PhD}$, with support for an extended period of research in a laboratory. Not only will this provide an opportunity for acquiring new skills, living in another country increases experience and confidence. In the long term such an experience will help the fellow to develop his or her career, and potentially compete better for positions at home, allowing development into an independent investigator, be it primarily in clinical research or continued as translational science. Moreover, these exchanges often initiate continued collaboration between the host and the home unit, which further helps to strengthen and develop the European research in respiratory medicine. 
In conclusion, the ERS has been investing significant resources in its fellowship programme. As judged from the outcomes and comments of the fellows and the home and host supervisors, the programme appears to be fulfilling an important set of ERS aims in serving the society, its members and finally, most importantly, patients with respiratory disease.

\section{References}

1 Moore A, Breithaupt $\mathrm{H}$. Where are they now? A survey of the career possibilities for young scientists in the life sciences. EMBO Rep 2001; 2: 8-10.

2 Ley TJ, Rosenberg LE. The physician-scientist career pipeline in 2005: build it, and they will come. JAMA 2005; 294: $1343-1351$. 